OPEN ACCESS

Edited by:

Michael Kogut,

United States Department of

Agriculture, United States

Reviewed by:

Venkatramana D. Krishna,

University of Minnesota Twin Cities,

United States

Santosh Dhakal,

Johns Hopkins University,

United States

*Correspondence: Jovita Fernández-Pinero fpinero@inia.es

Specialty section: This article was submitted to Veterinary Infectious Diseases, a section of the journal

Frontiers in Veterinary Science

Received: 15 January 2020

Accepted: 27 March 2020

Published: 21 April 2020

Citation:

Elizalde M, Cano-Gómez C, Llorente F, Pérez-Ramírez E, Casades-Martí L, Aguilera-Sepúlveda P, Ruiz-Fons F, Jiménez-Clavero MÁ and Fernández-Pinero J (2020) A Duplex Quantitative Real-Time Reverse Transcription-PCR for Simultaneous

Detection and Differentiation of

Flaviviruses of the Japanese Encephalitis and Ntaya

Serocomplexes in Birds.

Front. Vet. Sci. 7:203

doi: 10.3389/fvets.2020.00203

\section{A Duplex Quantitative Real-Time Reverse Transcription-PCR for Simultaneous Detection and Differentiation of Flaviviruses of the Japanese Encephalitis and Ntaya Serocomplexes in Birds}

\author{
Maia Elizalde ${ }^{1}$, Cristina Cano-Gómez ${ }^{1}$, Francisco Llorente ${ }^{1}$, Elisa Pérez-Ramírez ${ }^{1}$, \\ Laia Casades-Martí ${ }^{2}$, Pilar Aguilera-Sepúlveda ${ }^{1}$, Francisco Ruiz-Fons ${ }^{2}$, \\ Miguel Ángel Jiménez-Clavero ${ }^{1,3}$ and Jovita Fernández-Pinero ${ }^{1 *}$
}

${ }^{1}$ Centro de Investigación en Sanidad Animal (CISA), Instituto Nacional de Investigación y Tecnología Agraria y Alimentaria (INIA), Valdeolmos-Alalpardo, Spain, ${ }^{2}$ Instituto de Investigación de Recursos Cinegéticos IREC (CSIC-UCLM-JCCM), SaBio Group, Ciudad Real, Spain, ${ }^{3}$ Epidemiología y Salud Pública, CIBERESP, Madrid, Spain

High impact, mosquito-borne flaviviruses such as West Nile virus (WNV), Usutu virus (USUV), Japanese encephalitis virus (JEV), Tembusu virus (TMUV), and Bagaza/Israel turkey meningoencephalomyelitis virus (BAGV/ITV) are emerging in different areas of the world. These viruses belong to the Japanese encephalitis (JE) serocomplex (JEV, WNV, and USUV) and the Ntaya serocomplex (TMUV and BAGV/ITV). Notably, they share transmission route (mosquito bite) and reservoir host type (wild birds), and some of them co-circulate in the same areas, infecting overlapping mosquito and avian population. This may simplify epidemiological surveillance, since it allows the detection of different infections targeting the same population, but also represents a challenge, as the diagnostic tools applied need to detect the whole range of flaviviruses surveyed, and correctly differentiate between these closely related pathogens. To this aim, a duplex real-time RT-PCR (dRRT-PCR) method has been developed for the simultaneous and differential detection of JE and Ntaya flavivirus serocomplexes. The method has been standardized and evaluated by analyzing a panel of 49 flaviviral and non-flaviviral isolates, and clinical samples of different bird species obtained from experimental infections or from the field, proving its value for virus detection in apparently healthy or suspicious animals. This new dRRT-PCR technique is a reliable, specific and highly sensitive tool for rapid detection and differentiation of JE and Ntaya flavivirus groups in either domestic or wild animals. This novel method can be implemented in animal virology diagnostic laboratories as screening tool in routine surveillance and in the event of bird encephalitis emergence.

Keywords: flavivirus, Japanese encephalitis serocomplex, Ntaya serocomplex, West Nile virus, diagnostics, duplex real-time RT-PCR 


\section{INTRODUCTION}

The genus Flavivirus, within the family Flaviviridae, comprises more than 70 different viruses, many of which represent relevant pathogens for humans and animals $(1,2)$. Serological affinities allowed their classification into eight antigenic groups or serocomplexes (3). Two of these, namely Japanese encephalitis (JE) and Ntaya groups, comprise a number of pathogenic viruses associated with neurological diseases in different vertebrate species, including domestic species and human beings, being most of them potentially or factually zoonotic (4-7). Clinically relevant viruses within the JE group are, for instance, West Nile virus (WNV), Saint Louis encephalitis virus (SLEV), Japanese encephalitis virus (JEV), Murray Valley encephalitis virus (MVEV), and Usutu virus (USUV), while the Ntaya serocomplex includes Bagaza virus (BAGV), its synonymous Turkey meningoencephalomyelitis virus (ITV) (8), and Tembusu virus (TMUV). All these viruses are maintained in nature in a cycle involving avian reservoir hosts and Culex spp. mosquitoes. Also, all of them have caused an increasing number of outbreaks over the last years (9-11). In fact, the incidence and geographic spread of these flaviviral infections has risen dramatically worldwide and should be regarded as a threat to animal and human health (12). In Europe and the Mediterranean region, increasing flavivirus activity has been observed in recent times (13). The number of WNV outbreaks has intensely risen since late 1990's (14-16) and USUV has spread widely since its first detection in Austria in 2001 (17-19). In 2010, BAGV emerged in Southern Spain (20) in an area where WNV and USUV were co-circulating in the same avian population (21). Its synonymous virus, ITV, also re-emerged in Israel in the same time period (22). Likewise, in other areas of the world, similar patterns of flavivirus emergence are being observed, particularly involving those belonging to the JE and Ntaya groups $(7,23,24)$. Also, the risk of emergence of any of those viruses in distant territories should not be disregarded, as some members of these groups have demonstrated their capacity to undergo transcontinental displacements. Notably, WNV was able to reach the Americas in 1999, probably introduced from the Mediterranean area (25). Similarly, USUV and BAGV were able to reach Europe likely from Sub-Saharan Africa (12, 20, 26).

As the number of flaviviruses circulating in given geographic areas (such as those already mentioned) grows, molecular diagnosis of flaviviral infections relies more and more on generic RT-PCR approaches, which may be particularly advantageous in bird disease diagnostics and surveillance. However, panflavivirus PCR methods described so far are focused essentially on public health application or entomological surveillance (2733 ), and no PCR-based system is currently available for avian monitoring. Most important bird-pathogenic flaviviruses belong to the above-mentioned JE and Ntaya serocomplexes. The generic detection of viral species of both serocomplexes in a single test would potentially provide more accurate and rapid diagnostic results in monitoring programs, where high-sensitive methods are demanded for large screening. This study describes the development and standardization of a quantitative duplex real-time RT-PCR (dRRT-PCR) method for the simultaneous detection and differentiation of flaviviruses from the JE and Ntaya serocomplexes, to be used as a screening tool in routine avian surveillance and in the event of bird encephalitis outbreaks.

\section{MATERIALS AND METHODS}

\section{Viruses}

A collection of 49 different viral isolates was used for the development and standardization of the dRRT-PCR assay (Table 1). Briefly, a flavivirus panel composed of 27 isolates from JE serocomplex, 7 isolates from Ntaya serocomplex and 5 reference strains of other flavivirus species was employed. When needed, viral isolates were propagated and titrated by cell culture standard techniques. All flavivirus isolates used in the study belong to the virus collection held in reserve at INIA-CISA, Valdeolmos, Spain, and were originally obtained from different providers or collaborators as described in Table 1.

Additionally, a set of 10 avian or equine non-flavivirus isolates were analyzed in the specificity studies, namely: Avian influenza virus (AIV, subtypes H5N2, H7N1, H1N1), Newcastle disease virus (NDV), African horse sickness virus (AHSV, serotype 4), Western equine encephalitis virus (WEEV), Equine herpesvirus1 (EHV-1), Venezuelan equine encephalitis virus (VEEV), Equine influenza virus (EIV, subtype H3N8), and Vesicular stomatitis virus (VSV, Indiana serotype). AIV isolates were provided by IZSLER (Brescia, Italy); WEEV, EHV-1 and VEEV were obtained from ANSES (Maisons-Alfort, France); NDV, AHSV, EIV, and VSV belong to the virus collection maintained at INIA-CISA (Valdeolmos, Spain).

\section{Experimental and Field Samples}

Clinical samples collected from in vivo experiments carried out with different bird species (house sparrow, red-legged partridge and gray partridge) in the BSL-3 animal facilities at INIA-CISA (36-38) were used for this particular study. Specifically, a panel of 20 immature feathers, 20 blood samples and 24 tissues (heart, liver, brain, spleen, and kidney) obtained from non-infected control birds, and 2 blood, 2 immature feathers and 20 tissue samples collected at different times post-infection from birds experimentally inoculated with WNV or BAGV were analyzed (Table 2A).

On the other hand, a set of 9 WNV-positive (lineage 1) field samples (5 feathers, 2 swabs, and 2 brain samples) collected from different avian species were included in this study. The samples were obtained from WNV cases occurred in wild birds in Southern Spain, and were provided as WNV PCR positive by the National Reference Laboratory (NRL) for avian diseases, Laboratorio Central de Veterinaria (LCV, Algete, Spain). Seven samples (feather and tissues) obtained from a red-legged partridge found dead during the BAGV outbreaks occurred in Southern Spain in 2010, which was submitted by Estación Biológica de Doñana (EBD-CSIC, Seville, Spain) for diagnostic confirmation, were incorporated to this study (Table 2B).

In addition, a panel of 25 feathers and tissue samples (heart, liver, brain, lung, spleen and kidney), obtained from 4 individuals (2 little owls, 1 goshawk, and 1 crow) showing neurological 
TABLE 1 | Flavivirus isolates used in this study and results obtained by the dRRT-PCR and the RT-PCR methods used as reference.

\begin{tabular}{|c|c|c|c|c|c|c|c|c|c|}
\hline \multirow[t]{2}{*}{ Flavivirus sero complex } & \multirow[t]{2}{*}{ Virus } & \multirow[t]{2}{*}{ Isolate (lineage) } & \multirow{2}{*}{$\begin{array}{l}\text { Geographical } \\
\text { origin }\end{array}$} & \multirow[t]{2}{*}{ Species of origin } & \multirow{2}{*}{$\begin{array}{l}\text { Year of } \\
\text { isolation }\end{array}$} & \multirow[t]{2}{*}{ Source } & \multicolumn{2}{|c|}{ Duplex RRT-PCR } & \multirow[t]{2}{*}{ Reference PCR } \\
\hline & & & & & & & Fam (JE) & Joe (Ntaya) & \\
\hline \multirow[t]{20}{*}{ Japanese encephalitis (JE) } & WNV & $\mathrm{E}-101(1 \mathrm{a})$ & Egypt & Human & 1951 & $\begin{array}{l}\text { Institut Pasteur } \\
\text { Lyon (France) }\end{array}$ & 21.33 & No Ct & $22.8^{\mathrm{a}}$ \\
\hline & & IS-98 STD (1a) & Israel & White stork & 1998 & ANSES (France) & 29.55 & No Ct & $31.2^{\mathrm{a}}$ \\
\hline & & NY99 034EDV (1a) & New York & American crow & 1999 & $\begin{array}{l}\text { Diagnostic } \\
\text { Virology } \\
\text { Laboratory USDA } \\
\text { Ames (USA) }\end{array}$ & 17.34 & No Ct & $17.02^{\mathrm{a}}$ \\
\hline & & $04.05(1 \mathrm{a})$ & Morocco & Horse & 2003 & $\begin{array}{l}\text { Biopharma Rabat } \\
\text { (Morocco) }\end{array}$ & 18.26 & No Ct & $19.57^{\mathrm{a}}$ \\
\hline & & GE-1b/B (1a) & Spain & Golden eagle & 2007 & $\begin{array}{l}\text { INIA-CISA Madrid } \\
\text { (Spain) }\end{array}$ & 18 & No Ct & $19.73^{\mathrm{a}}$ \\
\hline & & $15803(1 a)$ & Italy & Magpie & 2008 & $\begin{array}{l}\text { IZSLER Brescia } \\
\text { (Italy) }\end{array}$ & 23.48 & No Ct & $26.61^{a}$ \\
\hline & & 225677/2009 (1a) & Italy & Jay & 2009 & $\begin{array}{l}\text { IZSLER Brescia } \\
\text { (Italy) }\end{array}$ & 24.55 & No Ct & $25.46^{\mathrm{a}}$ \\
\hline & & 233184/4/2009 (1a) & Italy & Black headed gull & 2009 & $\begin{array}{l}\text { IZSLER Brescia } \\
\text { (Italy) }\end{array}$ & 24.19 & No Ct & $26.87^{a}$ \\
\hline & & Spain/2010/H-1b (1a) & Spain & Horse & 2010 & $\begin{array}{l}\text { INIA-CISA Madrid } \\
\text { (Spain) }\end{array}$ & 20.74 & No Ct & $20.98^{\mathrm{a}}$ \\
\hline & & Spain/2012 (1a) & Spain & Horse & 2012 & LCV Algete (Spain) & 19.35 & No Ct & $20.57^{\mathrm{a}}$ \\
\hline & & Kunjin KJ359-11 (1b) & Australia & Horse & 1984 & $\begin{array}{l}\text { ISCIII Madrid } \\
\text { (Spain) }\end{array}$ & 29.4 & No Ct & $33.67^{a}$ \\
\hline & & B956 (2) & Uganda & Human & 1937 & ATCC (USA) & 16.53 & No Ct & $17.07^{\mathrm{a}}$ \\
\hline & & Austria/2008 (2) & Austria & Goshawk & 2008 & $\begin{array}{l}\text { VetMedUni Vienna } \\
\text { (Austria) }\end{array}$ & 26.48 & No Ct & $31.8^{\mathrm{a}}$ \\
\hline & & WN/Horse/RSA/1/08 (2) & South Africa & Horse & 2008 & $\begin{array}{l}\text { Onderstepoort } \\
\text { Veterinary Institute } \\
\text { Pretoria (South } \\
\text { Africa) }\end{array}$ & 31.48 & No Ct & $35.22^{\mathrm{a}}$ \\
\hline & & $178907 / 2013(2)$ & Italy & Culex pipiens & 2013 & $\begin{array}{l}\text { IZSLER Brescia } \\
\text { (Italy) }\end{array}$ & 16.72 & No Ct & $19.32^{\mathrm{a}}$ \\
\hline & & Rabensburg 97-103 (3) & $\begin{array}{l}\text { Czech } \\
\text { Republic }\end{array}$ & Culex pipiens & 1997 & $\begin{array}{l}\text { ISCIII Madrid } \\
\text { (Spain) }\end{array}$ & 18.78 & No Ct & $\operatorname{Pos}^{\mathrm{c}}$ \\
\hline & & MP502-66 (putative 6) & Malaysia & Culex pseudovishnui & 1966 & $\begin{array}{l}\text { ISCIII Madrid } \\
\text { (Spain) }\end{array}$ & 25.86 & No Ct & $\operatorname{Pos}^{c}$ \\
\hline & & Koutango ArD96655 (putative 7) & Senegal & Rhipicephalus guihoni & 1993 & $\begin{array}{l}\text { Institute Pasteur } \\
\text { Dakar (Senegal) }\end{array}$ & 16.42 & No Ct & $\mathrm{Pos}^{\mathrm{c}}$ \\
\hline & USUV & SAAR 1776/1958 & South Africa & Culex neavei & 1958 & ANSES (France) & 24.77 & No Ct & $28.31^{\mathrm{a}}$ \\
\hline & & 939 & Austria & Blackbird & 2001 & $\begin{array}{l}\text { ISCIII Madrid } \\
\text { (Spain) }\end{array}$ & 19.9 & No Ct & $22.25^{\mathrm{a}}$ \\
\hline
\end{tabular}


TABLE 1 | Continued

\begin{tabular}{|c|c|c|c|c|c|c|c|c|c|}
\hline \multirow[t]{2}{*}{ Flavivirus sero complex } & \multirow[t]{2}{*}{ Virus } & \multirow[t]{2}{*}{ Isolate (lineage) } & \multirow{2}{*}{$\begin{array}{l}\text { Geographical } \\
\text { origin }\end{array}$} & \multirow[t]{2}{*}{ Species of origin } & \multirow{2}{*}{$\begin{array}{c}\text { Year of } \\
\text { isolation }\end{array}$} & \multirow[t]{2}{*}{ Source } & \multicolumn{2}{|c|}{ Duplex RRT-PCR } & \multirow[t]{2}{*}{ Reference PCR } \\
\hline & & & & & & & Fam (JE) & Joe (Ntaya) & \\
\hline & & $231247 / 2011$ & Italy & Blackbird & 2011 & $\begin{array}{l}\text { IZSLER Brescia } \\
\text { (Italy) }\end{array}$ & 22.19 & No Ct & $25.37^{\mathrm{a}}$ \\
\hline & & 206795-3/2012 & Italy & Culex pipiens & 2012 & $\begin{array}{l}\text { IZSLER Brescia } \\
\text { (Italy) }\end{array}$ & 24.77 & No Ct & $28.31^{a}$ \\
\hline & & $229615-1 / 2013$ & Italy & Culex pipiens & 2013 & $\begin{array}{l}\text { IZSLER Brescia } \\
\text { (Italy) }\end{array}$ & 23.3 & No Ct & $28.11^{\mathrm{a}}$ \\
\hline & & HautRhin7315/France/2015 & France & Blackbird & 2015 & ANSES (France) & 25.39 & No Ct & $28.27^{\mathrm{a}}$ \\
\hline & JEV & Nakayama & Japan & - & 1935 & $\begin{array}{l}\text { ISCIII Madrid } \\
\text { (Spain) }\end{array}$ & 23.9 & No Ct & $\operatorname{Pos}^{c}$ \\
\hline & MVEV & MV/1/1951 & - & - & 1951 & $\begin{array}{l}\text { ISCIII Madrid } \\
\text { (Spain) }\end{array}$ & 26.91 & No Ct & $\operatorname{Pos}^{\mathrm{C}}$ \\
\hline & SLEV & FL52 & - & - & - & $\begin{array}{l}\text { ISCIII Madrid } \\
\text { (Spain) }\end{array}$ & 38 & No Ct & $\mathrm{Neg}^{\mathrm{C}}$ \\
\hline \multirow[t]{7}{*}{ Ntaya } & BAGV & Spain H/2010 & Spain & Red-legged partridge & 2010 & $\begin{array}{l}\text { INIA-CISA Madrid } \\
\text { (Spain) }\end{array}$ & No Ct & 25.46 & $24.71^{b}$ \\
\hline & ITV & Vaccine strain & Israel & Domestic turkey & 1985 & $\begin{array}{l}\text { Kimron Veterinary } \\
\text { Institute (Israel) }\end{array}$ & No Ct & 27.73 & $26.74^{b}$ \\
\hline & & 618 & Israel & Domestic turkey & 1995 & $\begin{array}{l}\text { Kimron Veterinary } \\
\text { Institute (Israel) }\end{array}$ & No Ct & 26.34 & $24.53^{b}$ \\
\hline & & 107458 & Israel & Domestic turkey & 2010 & $\begin{array}{l}\text { Kimron Veterinary } \\
\text { Institute (Israel) }\end{array}$ & No Ct & 19.19 & $17.61^{b}$ \\
\hline & & 106819 & Israel & Domestic turkey & 2010 & $\begin{array}{l}\text { Kimron Veterinary } \\
\text { Institute (Israel) }\end{array}$ & No Ct & 29.11 & $27.68^{b}$ \\
\hline & & 105520 & Israel & Domestic turkey & 2010 & $\begin{array}{l}\text { Kimron Veterinary } \\
\text { Institute (Israel) }\end{array}$ & No Ct & 30.69 & $27.96^{b}$ \\
\hline & TMUV & UVE/TMUV/1955/MY/MM1775 & Malaysia & Culex tritaeniorhinchus & 1955 & $\begin{array}{l}\text { European Virus } \\
\text { Archive (EVAg) }\end{array}$ & No Ct & 19.85 & $\operatorname{Pos}^{\mathrm{c}}$ \\
\hline \multirow[t]{5}{*}{ Other flaviviruses } & TBEV & Neudorfl & - & - & - & $\begin{array}{l}\text { ISCIII Madrid } \\
\text { (Spain) }\end{array}$ & No Ct & No Ct & $\operatorname{Pos}^{\mathrm{c}}$ \\
\hline & & Hypr & - & - & - & ANSES (France) & No Ct & No Ct & $\operatorname{Pos}^{c}$ \\
\hline & LIV & - & - & - & - & $\begin{array}{l}\text { ISCIII Madrid } \\
\text { (Spain) }\end{array}$ & No Ct & No Ct & Pos $^{\mathrm{C}}$ \\
\hline & ZIKV & - & - & - & - & $\begin{array}{l}\text { ISCIII Madrid } \\
\text { (Spain) }\end{array}$ & No Ct & No Ct & $\operatorname{Pos}^{\mathrm{C}}$ \\
\hline & DENV & Hawaii & - & - & - & $\begin{array}{l}\text { ISCIII Madrid } \\
\text { (Spain) }\end{array}$ & No Ct & No Ct & $\operatorname{Pos}^{c}$ \\
\hline
\end{tabular}

TBEV, Tick-borne encephalitis virus; LIV, Louping-ill virus; ZIKV, Zika virus; DENV, Dengue virus.

${ }^{a}$ Del Amo et al. (34). ${ }^{b}$ Buitrago et al. (35). ${ }^{\circ}$ Scaramozzino et al. (27). 
TABLE 2A / Clinical samples used in this study and results obtained by the dRRT-PCR and the RT-PCR methods used as reference; experimental samples from in vivo experiments performed at INIA-CISA.

\begin{tabular}{|c|c|c|c|c|c|c|c|c|c|c|}
\hline \multirow[t]{2}{*}{ Virus } & \multirow[t]{2}{*}{ Species } & \multirow[t]{2}{*}{ Animal Id } & \multirow{2}{*}{$\begin{array}{l}\text { Type of } \\
\text { Sample }\end{array}$} & \multirow[t]{2}{*}{ DPI* } & \multicolumn{2}{|c|}{ DUPLEX RRT-PCR } & \multicolumn{3}{|c|}{ WNV-1/WNV-2/USUV RRT-PCR ${ }^{a}$} & \multirow[t]{2}{*}{ BAGV RRT-PCR ${ }^{b}(C t)$} \\
\hline & & & & & JE (Ct) & NTAYA (Ct) & WNV-1 (Ct) & WNV-2 (Ct) & USUV (Ct) & \\
\hline \multirow{5}{*}{$\begin{array}{l}\text { WNV L1 (GE-1b/B } \\
\text { Spain 2007) }\end{array}$} & \multirow[t]{5}{*}{ House sparrow } & \multirow[t]{5}{*}{11} & Brain & \multirow[t]{5}{*}{7} & 28.44 & No Ct & 31.25 & No Ct & No Ct & \\
\hline & & & Kidney & & 27.37 & No Ct & 29.15 & No Ct & No Ct & \\
\hline & & & Spleen & & 24.01 & No Ct & 25.68 & No Ct & No Ct & \\
\hline & & & Heart & & 26.85 & No Ct & 28.53 & No Ct & No Ct & \\
\hline & & & Liver & & 24.78 & No Ct & 27.15 & No Ct & No Ct & \\
\hline \multirow[t]{7}{*}{ WNV L2 (Austria/2008) } & \multirow{7}{*}{$\begin{array}{l}\text { Red-legged } \\
\text { partridge }\end{array}$} & \multirow[t]{7}{*}{7} & Brain & \multirow[t]{7}{*}{7} & 28.41 & No Ct & No Ct & 32.45 & No Ct & \\
\hline & & & Kidney & & 26.43 & No Ct & No Ct & 31.20 & No Ct & \\
\hline & & & Spleen & & 27.6 & No Ct & No Ct & 35.19 & No Ct & \\
\hline & & & Heart & & 24.48 & No Ct & No Ct & 30.89 & No Ct & \\
\hline & & & Liver & & 36.75 & No Ct & No Ct & 39.03 & No Ct & \\
\hline & & & Blood & & 35.84 & No Ct & No Ct & No Ct & No Ct & \\
\hline & & & Feather & & 23.38 & No Ct & No Ct & 30.01 & No Ct & \\
\hline \multirow[t]{12}{*}{ BAGV (Spain H/2010) } & \multirow{5}{*}{$\begin{array}{l}\text { Red-legged } \\
\text { partridge }\end{array}$} & \multirow[t]{5}{*}{4} & Brain & \multirow[t]{5}{*}{6} & No Ct & 31.19 & & & & 29.54 \\
\hline & & & Kidney & & No Ct & 26.17 & & & & 25.81 \\
\hline & & & Spleen & & No Ct & 24.31 & & & & 25.69 \\
\hline & & & Heart & & No Ct & 23.47 & & & & 25.81 \\
\hline & & & Liver & & No Ct & 26.05 & & & & 26.84 \\
\hline & \multirow[t]{7}{*}{ Grey partridge } & \multirow[t]{7}{*}{4} & Brain & \multirow[t]{7}{*}{4} & No Ct & 35.83 & & & & 27.11 \\
\hline & & & Kidney & & No Ct & 22.97 & & & & 21.19 \\
\hline & & & Spleen & & No Ct & 24.27 & & & & 19.66 \\
\hline & & & Heart & & No Ct & 29.16 & & & & 20.5 \\
\hline & & & Liver & & No Ct & 26.37 & & & & 22.45 \\
\hline & & & Blood & & No Ct & 24.95 & & & & 20.81 \\
\hline & & & Feather & & No Ct & 23.28 & & & & 19.98 \\
\hline
\end{tabular}

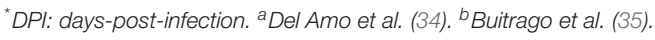

disorders were also incorporated in the study. These samples remained undiagnosed and were submitted by the Veterinary Faculty of Universidad de Extremadura (UEX, Cáceres, Spain) for diagnostic investigation (Table 2B).

Finally, the dRRT-PCR technique was transferred to IREC (Ciudad Real, Spain) and applied in a surveillance study of wild birds in Castilla-La Mancha (Spain). Briefly, a total of 237 birds were sampled, belonging to the following families: Alcedinidae ( $n$ $=1)$, Certhiidae $(n=6)$, Corvidae $(n=20)$, Emberizidae $(n=$ $15)$, Fringillidae $(n=10)$, Hirundinidae $(n=13)$, Laniidae $(n=$ $8)$, Muscicapidae $(n=1)$, Oriolidae $(n=1)$, Paridae $(n=61)$, Passeridae $(n=36)$, Prunellidae $(n=1)$, Sylviidae $(n=27)$, and Turdidae $(n=36)$. As far as possible, blood, immature feathers and oral and cloacal swabs were collected; the feather being the sample tested, when available, in the PCR screening.

\section{Nucleic Acid Extraction}

Total RNA was extracted at INIA-CISA (Valdeolmos, Spain) from $200 \mu \mathrm{l}$ of sample (virus suspension, blood, feathers, swabs and tissue homogenates $10 \%$ in PBS) using the automated BioSprint 15 workstation and the BioSprint DNA blood kit (Qiagen, Valencia, CA), according to manufacturer's instructions with small modifications (carrier RNA was added to AL buffer for a final concentration of $5 \mu \mathrm{g} / \mathrm{ml})$. Finally, RNA was recovered in $100 \mu \mathrm{l}$ of nuclease-free water.

The Macherey-Nagel NucleoSpin TriPrep kit (Fisher Scientific, Leicestershire, UK) was used for RNA extraction of field samples at IREC (Ciudad Real, Spain), following the protocol recommended by the manufacturer, using $200 \mu \mathrm{l}$ of sample and recovering RNA in $50 \mu \mathrm{l}$ of nuclease-free water.

\section{Duplex Real-Time RT-PCR: Design and Methodology}

A comprehensive selection of Ntaya and JE serocomplex viruses' full-length genome sequences available from GenBank was individually aligned using Clustal Omega software (European Bioinformatic Institute, Hinxton, Cambridge CB10 1SD, UK). Two primers and TaqMan probe set, each specific for one serogroup covering all representative virus species were designed, targeting non-structural protein 2A (NS2A) gene and 3' end noncoding region ( $\left.3^{\prime} \mathrm{NCR}\right)$ for JE and Ntaya groups, respectively. Properties of the designed primers and probes were analyzed in silico with Primer Express 2.0 (Applied Biosystems, Life Technologies Corporation, Carlsbad, CA, USA). Probes were labeled with different reporter dyes, FAM for JE serocomplex and JOE for Ntaya serocomplex, to allow a simultaneous, but differential detection of both groups in a single run (Table 3 ). 
TABLE 2B | Clinical samples used in this study and results obtained by the dRRT-PCR and the RT-PCR methods used as reference; field samples from wild birds collected in Spain.

\begin{tabular}{|c|c|c|c|c|c|c|c|c|c|}
\hline \multirow[t]{2}{*}{ Virus } & \multirow[t]{2}{*}{ Species } & \multirow{2}{*}{$\begin{array}{l}\text { Source/ } \\
\text { Animal Id }\end{array}$} & \multirow{2}{*}{$\begin{array}{l}\text { Type of } \\
\text { Sample }\end{array}$} & \multicolumn{2}{|c|}{ DUPLEX RRT-PCR } & \multicolumn{3}{|c|}{ WNV-1/WNV-2/USUV RRT-PCR ${ }^{a}$} & \multirow[t]{2}{*}{ BAGV RRT-PCR ${ }^{\mathrm{b}}$ (Ct) } \\
\hline & & & & JE (Ct) & NTAYA (Ct) & WNV-1 (Ct) & WNV-2 (Ct) & USUV (Ct) & \\
\hline \multirow[t]{22}{*}{ WNV L1 } & \multirow{3}{*}{$\begin{array}{l}\text { Red-legged } \\
\text { partridge }\end{array}$} & LCV/30/11 & Brain & 28.54 & No Ct & 31.36 & No Ct & No Ct & \\
\hline & & LCV/2496/15 & Cloacal swab & 38.10 & No Ct & 33.71 & No Ct & No Ct & \\
\hline & & LCV/3179/13 & Oral swab & 31.60 & No Ct & 34.83 & No Ct & No Ct & \\
\hline & White stork & $\begin{array}{l}\text { LCV/2439/16- } \\
1\end{array}$ & Feather & 36.89 & No Ct & No Ct & No Ct & No Ct & \\
\hline & \multirow[t]{2}{*}{ Black vulture } & $\begin{array}{l}\text { LCV/2442/16- } \\
5\end{array}$ & Brain & 24.34 & No Ct & 28.17 & No Ct & No Ct & \\
\hline & & $\begin{array}{l}\text { LCV/2442/16- } \\
4\end{array}$ & Feather & 28.28 & No Ct & 30.75 & No Ct & No Ct & \\
\hline & $\begin{array}{l}\text { Cinereous } \\
\text { vulture }\end{array}$ & $\begin{array}{l}\text { LCV/2442/16- } \\
3\end{array}$ & Feather & 31.66 & No Ct & 31.49 & No Ct & No Ct & \\
\hline & \multirow[t]{2}{*}{ Duck } & $\begin{array}{l}\text { LCV/2439/16- } \\
11\end{array}$ & Feather & 27.58 & No Ct & 30.43 & No Ct & No Ct & \\
\hline & & LCV/2858/16 & Feather & 34.10 & No Ct & 39.15 & No Ct & No Ct & \\
\hline & \multirow[t]{13}{*}{ Little owl } & \multirow[t]{6}{*}{ UEX/10B } & Feather & 22.34 & No Ct & 26.36 & No Ct & No Ct & \\
\hline & & & Brain & 24.65 & No Ct & 25.69 & No Ct & No Ct & \\
\hline & & & Liver & 24.67 & No Ct & 27.64 & No Ct & No Ct & \\
\hline & & & Lung & 18.79 & No Ct & 21.54 & No Ct & No Ct & \\
\hline & & & Heart & 23.21 & No Ct & 26.09 & No Ct & No Ct & \\
\hline & & & Spleen & 34.38 & No Ct & 38.32 & No Ct & No Ct & \\
\hline & & \multirow[t]{7}{*}{ UEX/A } & Feather & 19.38 & No Ct & 22.26 & No Ct & No Ct & \\
\hline & & & Brain & 27.62 & No Ct & 29.25 & No Ct & No Ct & \\
\hline & & & Liver & 25.26 & No Ct & 28.48 & No Ct & No Ct & \\
\hline & & & Lung & 18.85 & No Ct & 21.89 & No Ct & No Ct & \\
\hline & & & Heart & 19.70 & No Ct & 22.96 & No Ct & $\mathrm{No} C t$ & \\
\hline & & & Spleen & 26.77 & No Ct & 30.64 & No Ct & No Ct & \\
\hline & & & Kidney & 24.21 & No Ct & 25.51 & No Ct & No Ct & \\
\hline \multirow[t]{2}{*}{ USUV } & \multirow{2}{*}{$\begin{array}{l}\text { Common } \\
\text { blackbird }\end{array}$} & \multirow[t]{2}{*}{ IREC/A18/177 } & Oral swab & 35.99 & No Ct & No Ct & No Ct & 39.37 & \\
\hline & & & Cloacal swab & No Ct & No Ct & No Ct & No Ct & No Ct & \\
\hline \multirow[t]{7}{*}{ BAGV } & \multirow{7}{*}{$\begin{array}{l}\text { Red-legged } \\
\text { partridge }\end{array}$} & \multirow[t]{7}{*}{$\mathrm{EBD} / 2010 \mathrm{~A}$} & Feather & No Ct & 24.98 & & & & 23.26 \\
\hline & & & Brain & No Ct & 28.98 & & & & 28.62 \\
\hline & & & Kidney & No Ct & 28.86 & & & & 28.3 \\
\hline & & & Eye & No Ct & 22.72 & & & & 22.47 \\
\hline & & & Heart & No Ct & 32.93 & & & & 33.13 \\
\hline & & & Muscle & No Ct & 32 & & & & 32.08 \\
\hline & & & Skin & No Ct & 29.98 & & & & 28.34 \\
\hline
\end{tabular}

Only the results of the individuals giving positive result to any JE or Ntaya flavivirus serogroup are shown. ${ }^{a}$ Del Amo et al. (34). ${ }^{b}$ Buitrago et al. (35).

A BLASTn search of the selected primers and probes sequences against the GenBank database confirmed the specificity to the corresponding JE or Ntaya flavivirus serogroup.

Initially, RRT-PCR assays were optimized individually for JE or Ntaya serocomplex detection under the same reaction conditions, to be afterwards modified into a duplex format using the commercial AgPath-ID one-step RT-PCR kit (Life Technologies, Thermo Fisher Scientific, USA). For the dRRTPCR, a reaction mix was prepared containing (per vial) 3 $\mu \mathrm{l}$ of RNA template, $0.75 \mu \mathrm{M}$ of each primer and $0.2 \mu \mathrm{M}$ of each probe (Table 3), $0.8 \mu$ l of 25X RT-PCR enzyme mix (containing ArrayScript ${ }^{\mathrm{TM}}$ Reverse Transcriptase and AmpliTaq Gold ${ }^{\circledR}$ DNA Polymerase) and $10 \mu$ l of 2X RT-PCR Buffer (includes $\mathrm{ROX}^{\mathrm{TM}}$ passive reference dye for quantitative fluorescent signal normalization), and nuclease-free water to reach a reaction volume of $20 \mu \mathrm{l}$. Reaction mixes for individual RRT-PCR assays were prepared with same reagents, volumes and concentrations described for the dRRT-PCR, except only primers/probe for the target flaviviral serocomplex were added.

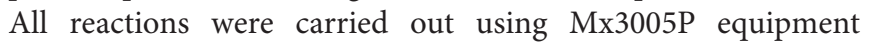
and software (Stratagene Inc., La Jolla, CA, USA) using the following thermal profile: reverse transcription at $48^{\circ} \mathrm{C}$ 
TABLE 3 | List of primers and probes designed for the detection of JE and Ntaya serocomplexes by dRRT-PCR assay.

\begin{tabular}{|c|c|c|c|c|}
\hline Primer/Probe name & Sequence and labeling $\left(5^{\prime} \rightarrow 3^{\prime}\right)^{\mathrm{a}}$ & Nucleotide positions & Product size & Target genome region \\
\hline \multicolumn{5}{|c|}{ Japanese encephalitis serocomplex } \\
\hline JE-3533F & TCAGYTGGGCCTTCTGGT & $3,533-3,550^{b}$ & $65 \mathrm{bp}$ & NS2A \\
\hline JE-3597R & TGGCCGTCCACCTCTTSC & $3,597-3,580^{b}$ & & \\
\hline JE-FAM-3553 & 6FAM-TGTTYTTGGCCACCCAGGAGGT -BHQ1 & $3,553-3,574^{b}$ & & \\
\hline \multicolumn{5}{|l|}{ Ntaya Serocomplex } \\
\hline NT-10510F & GTTGGATGACGGTGCWGYCTG & $10,510-10,530^{c}$ & $171 \mathrm{bp}$ & $3^{\prime}$ NTR \\
\hline NT-10680R & GCTGCACTGCATGCTARTGGC & $10,680-10,660^{c}$ & & \\
\hline NT-JOE-10594 & JOE-TACCGWCTCGGAGARCTCCCTGGC-BHQ1 & $10,594-10,617^{c}$ & & \\
\hline
\end{tabular}

Primers and probes were purchased from Roche Applied Science (Spain).

a Code for mixed bases positions: R:AVG, Y:C/T, S:G/C, and W:A/T.

${ }^{b}$ Nucleotide positions regarding to the WNV L1 Spain/2010/H-1b strain. GenBank accession no. JF719069.

${ }^{c}$ Nucleotide positions regarding to the BAGV Spain H/2010 strain. GenBank accession no. HQ644143.

for $20 \mathrm{~min}$, initial PCR activation step at $95^{\circ} \mathrm{C}$ for $10 \mathrm{~min}$, followed by 45 cycles of $15 \mathrm{~s}$ at $95^{\circ} \mathrm{C}$ and $1 \mathrm{~min}$ at $60^{\circ} \mathrm{C}$. The fluorescence signal emitted by FAM and JOE reporter dyes was measured simultaneously and independently at the end of each cycle. A threshold cycle value $(\mathrm{Ct})>40$ was set as negative result.

\section{Construction of in vitro-Transcribed RNA Standards}

Two ssRNA standard controls were produced for analytical sensitivity estimation of the dRRT-PCR. Specifically, WNVL1 GE-1b/B and BAGV Spain H/2010 strains were used as templates in a PCR using outer primers of the duplex assay. The resulting products were sequenced to ensure the specificity of the amplification. Likewise, the cDNAs were gel-purified with Wizard SV Gel and PCR Clean-Up System (Promega, USA) and quantified by spectrophotometry. Each cDNA was cloned into pGEM-T easy vector system (Promega, USA) and DNA plasmids were further purified using Wizard Plus SV Miniprep DNA purification system (Promega, USA) and finally quantified by spectrophotometry. In vitro transcription was performed with Riboprobe ${ }^{\circledR}$ in vitro Transcription System (Promega, USA) over linearized DNA plasmid, following the manufacturer's instructions. RNA transcripts were then purified using MEGAclear Transcription Clean-Up Kit (Ambion, Thermo Fisher Scientific, USA), treated with $2 \mathrm{U}$ of Turbo ${ }^{\mathrm{TM}}$ DNase (Ambion, Thermo Fisher Scientific, USA) and re-purified with TriPure Isolation Reagent (Roche Applied Science, Germany). The produced RNA standards were quantified by ND-1000 NanoDrop spectrophotometer (Thermo Fisher Scientific, USA). Mean concentration values were $1.57 \mathrm{E}^{+11}$ and $4.72 \mathrm{E}^{+11}$ RNA copies/ $\mu 1$ for WNV-L1 and BAGV in vitro-transcribed RNA control preparations, respectively. A series of dilutions were generated for each quantified WNV and BAGV RNA and stored as standard RNA samples for further use in sensitivity assays.

Best-fit lines (standard curves) were calculated by the least squares regression method from the Ct values obtained for the serial dilutions of the two RNA standards produced to determine the dynamic range and detection limit of the dRRT-PCR method.

\section{Reference RT-PCR Methods}

Two previously validated techniques, namely a triplex RRT-PCR for WNV (lineages 1 and 2) and USUV simultaneous detection (34) and a single RRT-PCR for BAGV detection (35), were employed as reference methods in comparative assays. For detection of other flaviviruses, a widely used conventional RT-PCR (27) was performed with minor modifications, and amplification products were further sequenced to confirm the virus identity.

\section{RESULTS}

\section{Analytical Performance: Dynamic Range, Linearity, Efficiency, and Detection Limit}

Initially, the analytical sensitivity of the dRRT-PCR was studied by analyzing duplicates of 10 -fold serial dilutions of viral suspensions of WNV-L1 (Spain/2010/H-1b), WNV-L2 (B956), USUV (SAAR 1776/1958), and BAGV (Spain H/2010). All experiments were run in parallel with the equivalent reference RRT-PCR method $(34,35)$, obtaining a similar (BAGV) or at least 10 times higher (WNV-L1, WNV-L2, USUV) sensitivity with the dRRT-PCR (Supplementary Table 1).

The analytical performance of the dRRT-PCR method was assessed by analyzing the in vitro-transcribed RNA standards produced for WNV and BAGV, as above described. Specifically, the dilutions containing a range from $1.57 \mathrm{E}^{+8}$ to $1.57 \mathrm{E}^{+0}$ RNA copies/ $\mu$ l for WNV-L1 and $1.32 \mathrm{E}^{+7}$ to $1.32 \mathrm{E}^{+0}$ RNA copies $/ \mu \mathrm{l}$ for $\mathrm{BAGV}$ were tested in triplicates to construct the standard curves for both JE and Ntaya serocomplexes, respectively. The assays reacted in a dose-dependent manner with each reference RNA standard along a dynamic range of eight and seven 10-fold dilutions for both WNV-L1 and BAGV, respectively. The detection limit of the dRRT-PCR was estimated to be below 50 RNA copies for both JE and Ntaya serogroups. The standard curve produced with the WNV-L1 RNA standard showed a value of correlation coefficient (R) of 0.996 and efficiency rate (E) of 105.1\%. For BAGV RNA standard, R was 0.999 and the efficiency of the dRRT-PCR was 99.7\% (Figure 1, Supplementary Table 2). 

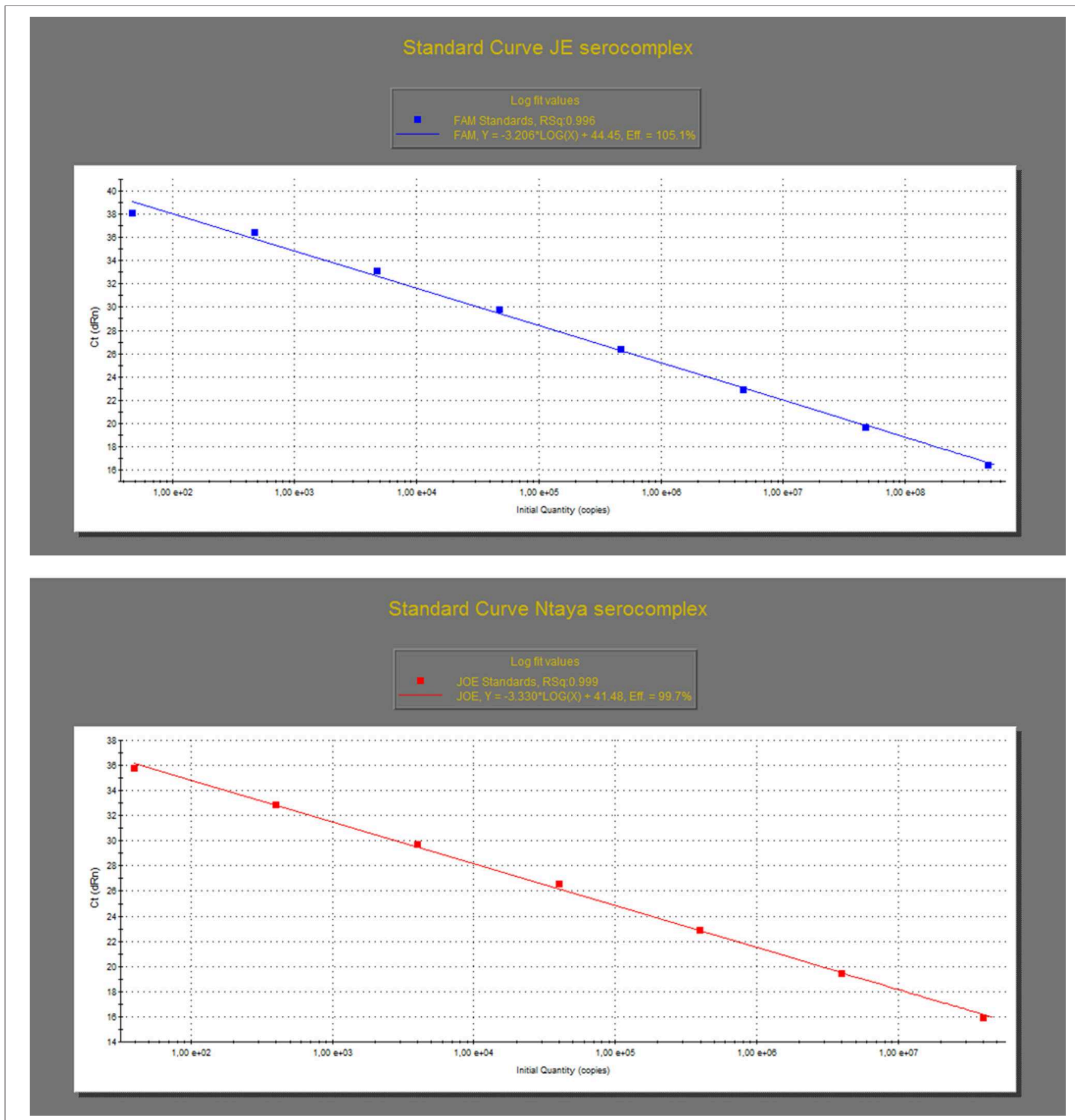

FIGURE 1 | Standard curves of the dRRT-PCR for the detection of JE (top graph) and Ntaya flavivirus serocomplexes (bottom graph). The curves were generated by analysis of triplicates of 10-fold serial dilutions of the quantified in vitro-transcribed WNV (top graph) and BAGV (bottom graph) RNA standards produced as synthetic positive controls. Each . corresponds to the mean value of three replicates.

Finally, the capacity of the dRRT-PCR to detect the presence of two target viruses in a single sample was evaluated with a set of WNV+BAGV RNA standards combinations. Specifically, dilutions of both RNA standards representing strong $(\mathrm{Ct}<20)$ and weak $(\mathrm{Ct}>33)$ positive samples were mixed in equivalent and disparate proportions. The panel of artificial "co-infected samples" were analyzed in triplicates and in parallel with triplicates of the corresponding "single infected samples." All preparations were correctly scored and Ct values were 
similar for each dilution analyzed pooled or individually (Supplementary Table 3).

\section{Specificity Assays and Detection Range}

To assess the analytical specificity of the dRRT-PCR, a panel of RNAs from 39 different flavivirus isolates and 10 avian and equine non-flavivirus isolates were analyzed. Fluorescence signals were obtained correctly for the range of JE and Ntaya serocomplex isolates analyzed, being able to clearly differentiate between them without any cross-reactions. The reference RRTPCR techniques were carried out in parallel for comparison, the dRRT-PCR reporting similar or lower $\mathrm{Ct}$ values for the range of WNV-L1, WNV-L2, and USUV isolates tested, while some slightly higher $\mathrm{Ct}$ values were obtained for BAGV/ITV isolates (Table 1). The specificity of the assay was further proved since no fluorescence signal was reported with any heterologous flavivirus (Table 1) and non-flavivirus isolates (data not shown).

\section{Performance With Clinical Samples}

The performance of the developed dRRT-PCR method for practical use in diagnosis was assessed initially by analyzing a panel of samples $(n=24)$, including blood, feathers, heart, spleen, liver, kidney, and brain, obtained from house sparrows, red-legged partridges and gray partridges experimentally infected with GE-1b/B Spain 2007 strain of WNV-L1, Austria/2008 strain of WNV-L2, or Spain H/2010 strain of BAGV, at INIA-CISA BSL-3 animal facilities (36-38). All experimental samples were correctly reported by the duplex assay, overall showing similar or lower Ct values for those samples infected with WNV-L1 or WNV-L2 than those obtained using the corresponding reference technique. For samples infected with BAGV, Ct values scored by the dRRT-PCR were generally higher than by the reference RRT-PCR (Table 2A). No fluorescence signal was obtained when experimental samples $(n=64)$ from non-infected control birds were tested, confirming the diagnostic specificity of the dRRTPCR (data not shown).

A first collection of WNV-L1 positive field samples $(n=$ 9) provided by the Spanish NRL was subjected to analysis to evaluate the diagnostic sensitivity of the dRRT-PCR. All feathers, swabs and tissues were scored correctly in the JE serocomplex. Running in parallel the reference RRT-PCR, most WNV-L1 samples reported lower Ct values in the dRRT-PCR, and even one feather was missed by the triplex reference method (Table 2B). In addition, all samples $(n=7)$ of a red-legged partridge (Alectoris rufa) found dead during the outbreaks of BAGV in 2010 were reported as positive for the Ntaya serocomplex by the dRRT-PCR, and were confirmed as BAGV positive by the reference technique. Similar $\mathrm{Ct}$ values were obtained for most samples by the two techniques (Table 2B).

To evaluate the competence of the dRRT-PCR with undiagnosed field material, a panel of feathers and tissue samples $(n=25)$ of different wild birds (2 little owls, 1 goshawk, and 1 crow), that had died with neurological signs, were examined in parallel by the dRRT-PCR and the two reference RRT-PCR techniques. An infection due to JE serocomplex virus was detected in all samples of the two little owls (Athene noctua) by the dRRT-PCR and WNV-L1 was identified by the triplex reference RRT-PCR, reporting the dRRT-PCR lower Ct values in all positive samples (Table 2B). Samples from the other two individuals remained negative by all assays.

Finally, the developed dRRT-PCR technique was implemented as screening tool in a surveillance study carried out in CastillaLa Mancha (Spain) by IREC. Of 237 sampled wild birds, 175 feathers, 58 oral swabs, and 4 cloacal swabs were analyzed. One feather from a common blackbird (Turdus merula) was found positive $(\mathrm{Ct}=15)$ for the JE serocomplex. Further sequencing confirmed the infection due to USUV in this bird. Unfortunately, this sample could not be analyzed by the triplex reference RRTPCR. Alternatively, oral and cloacal swabs of the same blackbird were examined at INIA-CISA by the dRRT-PCR and the WNVL1/WNV-L2/USUV triplex reference RRT-PCR, obtaining a weak positive signal in the oral swab for JE serocomplex and USUV, respectively (Table 2B).

\section{Repeatability Assessment}

Positive extraction controls employed throughout this study were used to assess the intra- and inter-assay repeatability of the dRRTPCR. These were prepared diluting two viral suspensions of WNV-L1 (as positive control for JE serocomplex) and BAGV (as positive control for Ntaya serocomplex) until getting the dilutions to give an expected $\mathrm{Ct}$ value of $30 \pm 2$ for each target. Aliquots of the two WNV and BAGV positive controls were stored at $-20^{\circ} \mathrm{C}$ and further included in each RNA extraction run.

The analysis of $10 \mathrm{WNV}$ and $10 \mathrm{BAGV}$ positive extraction controls in 10 duplex RRT-PCR runs proved the inter-assay repeatability, obtaining mean Ct values of 30.39 and 30.04, with a standard deviation (SD) of 0.59 and 0.43 , respectively. Finally, RNAs (stored at $-20^{\circ} \mathrm{C}$ ) from the same batch of WNV and BAGV positive extraction controls $(n=10+10)$ were tested in one single dRRT-PCR run to evaluate the intra-assay repeatability, giving a mean $\mathrm{Ct}$ value of $30.84(\mathrm{SD}=0.74)$ for $\mathrm{WNV}$ and of $30.57(\mathrm{SD}=0.59)$ for BAGV.

\section{DISCUSSION}

The recent emergence of different flaviviruses in wide regions of the world makes co-circulation of these pathogens in same geographic areas more likely $(12,13,39)$. Furthermore, there is a range of flavivirus species sharing vectors and hosts, producing similar disease pattern in susceptible animals. This is of current relevance for the Japanese encephalitis (JE) and Ntaya serogroups, which include Culex-borne viral species infecting the same bird population, in which they can produce a similar encephalitic disease. The increasing spread and incidence of the viruses belonging to these two groups requires that avian surveillance plans, in countries where they can potentially emerge and circulate, implement methods capable of detecting any of them. These methods could be of particular interest in certain geographic regions such as Southern Spain, Israel and several African countries (e.g., South Africa or Senegal) where WNV, USUV, and BAGV/ITV are present and infect bird and mosquito population $(21,40-42)$. 
Although some pan-flavivirus PCR methods have been described so far, most are focused on public health application or entomological surveillance (27-33), while none of them has been developed for birds. This is significant in the current epidemiological situation, where the recent and potential emergence of bird-pathogenic flaviviruses in different territories poses a complex challenge for the diagnostic laboratories and for the veterinary authorities. On the other hand, the combination of the relevant bird-pathogenic flaviviruses species (those belonging to the JE and Ntaya serocomplexes) in a single assay makes very difficult to develop a PCR test with the high sensitivity level demanded for a screening tool. This was solved, in this study, by designing a duplex RRT-PCR (dRRT-PCR) method for the generic and differential detection of these two target flavivirus serogroups. It is well-known that the design of generic molecular tools may be challenging to cover the range of target pathogens and may limit their sensitivity (43), especially when clinical material is analyzed. However, the new dRRT-PCR has demonstrated to be a specific and highly sensitive tool, capable of detecting the wide range of JE and Ntaya flaviviral species analyzed, and posing a performance similar to the RRT-PCR methods used as reference $(34,35)$. On the other hand, most PCR methods described for flaviviruses detection have been verified with human or mosquito samples, when available $(28,31-33)$. In this study, WNV, USUV and BAGV positive samples from a variety of wild bird species were available for the evaluation of the dRRT-PCR. The results analyzing an extensive panel of clinical material from experimental studies and from the field have proved its diagnostic capacity. In this regards, it deserves to point out the usefulness showed by the dRRT-PCR in the detection of viral infection in undiagnosed field samples (WNV in little owls) and in outbreak investigations (BAGV in red-legged partridge). Furthermore, the implementation of the dRRT-PCR technique in a wild bird monitoring study allowed the identification of a common blackbird infected with a JE-serogroup virus that was further confirmed as USUV. This is a relevant finding to support the potential value of this method for its use as a screening tool in routine diagnosis. Therefore, by combining two methods, one for $\mathrm{JE}$ and one for Ntaya in one duplex assay it is possible to detect a wide range of bird flaviviruses, including most important ones. In addition, by differentiating these two groups in one single analysis, we obtain a useful information to narrow the range of suspicious agents to analyse in a second, more specific method.

This quantitative method can also be used to estimate viral loads in blood and/or other organs or samples. Albeit not mandatory for diagnostic or surveillance studies, this ability can be used to monitor the clinical course of the infection and to determine if a given species develops enough viremia to act as a competent host (able to transmit the virus to the mosquito vector), which is essential to understand its role in the epidemiology of these flaviviruses.

Finally, the new dRRT-PCR was developed bearing in mind the current situation in some Mediterranean countries, where different flaviviruses of the two target serogroups have emerged and co-circulate in the avian population. However, this method can also be very useful in other geographic regions such as SouthEast Asia, where viruses belonging to the Ntaya serocomplex, e.g.,
Tembusu and Tembusu-related viruses, are spreading into areas where Japanese encephalitis virus is historically present $(23,44-$ 47). As well, according to the epidemiological scenario, the RRTPCR can be turned into individual tests for the only detection of JE or Ntaya serogroup providing equal diagnostic performance than the duplex format.

In conclusion, the duplex quantitative real-time RT-PCR described in this study provides a novel tool for the diagnostic and epidemiological surveillance of JE and Ntaya serocomplex flaviviruses, comprising a wide range of arboviral pathogens threatening animal and public health worldwide. This new method allows for the rapid detection and differentiation of these two serocomplexes being especially helpful as screening tool in bird flavivirus surveillance and in the diagnosis of avian encephalitis cases.

\section{DATA AVAILABILITY STATEMENT}

All datasets generated for this study are included in the article/Supplementary Material.

\section{ETHICS STATEMENT}

The animal study was reviewed and approved by INIA animal experimentation ethics committee and by the authorized organ of the Department of Environment and Land Management of the Community of Madrid.

\section{AUTHOR CONTRIBUTIONS}

JF-P conceived and designed the study, analyzed the data, and amended the article. ME participated in the design and development of the method and supervised the technical work. CC-G contributed to the design and development of the method and in the laboratory tests. CC-G, FL, and EP-R participated in sample selection and analysis and contributed to draft the article. PA-S contributed to sample selection and analysis. FR-F and LC-M collected and analyzed most of the field samples. MJ-C participated in the study design, coordination, and drafted the article. All authors read and approved the final manuscript.

\section{FUNDING}

This work has been funded by the Spanish Ministry of Agriculture, Food and Environment (MAGRAMA) under the INIA-MAGRAMA agreements EG13-020 and EG17-141, and by the Spanish Ministry for Science, Innovation and Universities (MCIU) under the project E-RTA2015-00002-C02. PA-S and LC$\mathrm{M}$ acknowledge funding from the Spanish Ministry for Science, Innovation and Universities (MCIU) by contract FPI-SGIT2016-05 and PEJ2018-003155-A, respectively.

\section{ACKNOWLEDGMENTS}

The authors acknowledge Ana Robles, Amalia Villalba, and Maria del Carmen Barbero Ameller for their excellent technical 
assistance during this work, and Encarnación Madueño for helping during the preparation of in vitro-transcribed RNA standards. Montserrat Agüero and Rubén Villalba from the Laboratorio Central de Veterinaria (LCV, Algete, Spain), Eva Frontera and Daniel Bravo from the Veterinary Faculty of the Universidad de Extremadura (UEX, Cáceres, Spain), and Jordi Figuerola from Estación Biológica de Doñana (EBD-CSIC, Seville, Spain) are acknowledged for providing field samples.

An abstract with preliminary results of this study was presented at the 10th ESVV/9th EPIZONE congress in

\section{REFERENCES}

1. Calisher $\mathrm{CH}$, Gould EA. Taxonomy of the virus family Flaviviridae. Adv Virus Res. (2003) 59:1-19. doi: 10.1016/S0065-3527(03)59001-7

2. Kuno G, Chang GJ, Tsuchiya KR, Cropp CB, Karabatsos N. Phylogeny of the genus flavivirus. J Virol. (1998) 72:73-83. doi: 10.1128/JVI.72.1.73-83.1998

3. Calisher $\mathrm{CH}$, Karabatsos N, Dalrymple JM, Shope RE, Porterfield JS, Westaway EG, et al. Antigenic relationships between flaviviruses as determined by cross-neutralization tests with polyclonal antisera. J Gen Virol. (1989) 70:37-43. doi: 10.1099/0022-1317-70-1-37

4. Gould EA, Solomon T. Pathogenic flaviviruses. Lancet. (2008) 371:5009. doi: 10.1016/S0140-6736(08)60238-X

5. Tang Y, Gao X, Diao Y, Feng Q, Chen H, Liu X, et al. Tembusu virus in human, China. Transbound Emerg Dis. (2013) 60:193-96. doi: 10.1111/tbed.12085

6. Bondre VP, Sapkal GN, Yergolkar PN, Fulmali P V, Sankararaman V, Ayachit $\mathrm{VM}$, et al. Genetic characterization of Bagaza virus (BAGV) isolated in India and evidence of anti-BAGV antibodies in sera collected from encephalitis patients. J Gen Virol. (2009) 90:2644-9. doi: 10.1099/vir.0.012336-0

7. Benzarti E, Linden A, Desmecht D, Garigliany M. Mosquito-borne epornitic flaviviruses: an update and review. J Gen Virol. (2019) 100:11932. doi: 10.1099/jgv.0.001203

8. Fernandez-Pinero J, Davidson I, Elizalde M, Perk S, Khinich Y, JimenezClavero MA. Bagaza virus and Israel turkey meningoencephalomyelitis virus are a single virus species. J Gen Virol. (2014) 95:8837. doi: 10.1099/vir.0.061465-0

9. Kurane I, Takasaki T, Yamada KI. Trends in flavivirus infections in Japan. Emerg Infect Dis. (2000) 6:569-71. doi: 10.3201/eid0606.000603

10. Daep CA, Muñoz-Jordán JL, Eugenin EA. Flaviviruses, an expanding threat in public health: focus on dengue, West Nile, and Japanese encephalitis virus. $J$ Neurovirol. (2014) 20:539-60. doi: 10.1007/s13365-014-0285-z

11. Holbrook MR. Historical perspectives on flavivirus research. Viruses. (2017) 9:97. doi: 10.3390/v9050097

12. Weissenböck H, Hubálek Z, Bakonyi T, Nowotny N. Zoonotic mosquitoborne flaviviruses: worldwide presence of agents with proven pathogenicity and potential candidates of future emerging diseases. Vet Microbiol. (2010) 140:271-80. doi: 10.1016/j.vetmic.2009.08.025

13. Beck C, Jimenez-Clavero MA, Leblond A, Durand B, Nowotny N, LeparcGoffart I, et al. Flaviviruses in europe: complex circulation patterns and their consequences for the diagnosis and control of west nile disease. Int J Environ Res Public Health. (2013) 10:6049-83. doi: 10.3390/ijerph10116049

14. Rizzoli A, Jimenez-Clavero M, Barzon L, Cordioli P, Figuerola J, Koraka P, et al. The challenge of West Nile virus in Europe : knowledge gaps and research priorities. Euro Surveill. (2015) 20:21135. doi: 10.2807/1560-7917.ES2015.20.20.21135

15. Busquets $N$, Laranjo-González $M$, Soler $M$, Nicolás $O$, Rivas $\mathrm{R}$, Talavera $\mathrm{S}$, et al. Detection of West Nile virus lineage 2 in North-Eastern Spain (Catalonia). Transbound Emerg Dis. (2019) 66:617-21. doi: 10.1111/tbed.13086

16. de Heus P, Kolodziejek J, Camp J V., Dimmel K, Bagó Z, Hubálek Z, et al. Emergence of West Nile virus lineage 2 in Europe: characteristics of the first seven cases of West Nile neuroinvasive disease in horses in Austria. Transbound Emerg Dis. (2019) 1-9. doi: 10.1111/tbed. 13452
Montpellier 2015, entitled Development of a duplex real-time qRT-PCR method for detection of flaviviruses belonging to Japanese encephalitis and Ntaya serogroups, and authored by ME, FL, EP-R, A. Robles, A., Villalba, M. C. Barbero, MJ-C; J F-P.

\section{SUPPLEMENTARY MATERIAL}

The Supplementary Material for this article can be found online at: https://www.frontiersin.org/articles/10.3389/fvets. 2020.00203/full\#supplementary-material
17. Weissenböck H, Kolodziejek J, Url A, Lussy H, Rebel-Bauder B, Nowotny N. Emergence of usutu virus, an African mosquito-borne flavivirus of the Japanese encephalitis virus group, central Europe. Emerg Infect Dis. (2002) 8:652-6. doi: 10.3201/eid0807.020094

18. Vazquez A, Jimenez-Clavero MA, Franco L, Donoso-Mantke O, Sambri V, Niedrig M, et al. Usutu virus: potential risk of human disease in Europe. Euro Surveill. (2011) 16:19935. doi: 10.2807/ese.16.31.19935-en

19. Roesch F, Moratorio G, Moratorio G, Vignuzzi M. Usutu virus: an arbovirus on the rise. Viruses. (2019) 11:640. doi: 10.3390/v11070640

20. Agüero M, Fernandez-Pinero J, Buitrago D, Sanchez A, Elizalde M, San Miguel E, et al. Bagaza virus in partridges and pheasants, Spain, 2010. Emerg Infect Dis. (2011) 17:1498-501. doi: 10.3201/eid1708.110077

21. Llorente F, Pérez-Ramírez E, Fernández-Pinero J, Soriguer R, Figuerola J, Jiménez-Clavero MA. Flaviviruses in game birds, southern Spain, 2011-2012. Emerg Infect Dis. (2013) 19:1023-5. doi: 10.3201/eid1906.130122

22. Davidson I, Raibstein I, Al-Tori A, Khinich Y, Simanov M, Yuval C, et al. Development of a reliable dual-gene amplification RT-PCR assay for the detection of Turkey Meningoencephalitis virus in Turkey brain tissues. J Virol Methods. (2012) 185:239-43. doi: 10.1016/j.jviromet.2012.06.001

23. Mackenzie JS, Williams DT. The zoonotic flaviviruses of southern, south-eastern and eastern Asia, and Australasia: the potential for emergent viruses. Zoonoses Public Health. (2009) 56:338-56. doi: 10.1111/j.1863-2378.2008.01208.x

24. Gill CM, Kapadia RK, Beckham JD, Piquet AL, Tyler KL, Pastula DM. Usutu virus disease: a potential problem for North America? J Neurovirol. (2019) doi: 10.1007/s13365-019-00818-y. [Epub ahead of print].

25. Lanciotti R, Roehrig J, Deubel V, Smith J, Parker M, Steele K, et al. Origin of the West Nile virus responsible for an outbreak of encephalitis in the northeastern United States. Science. (1999) 286:233337. doi: $10.1126 /$ science.286.5448.2333

26. Weissenböck H, Bakonyi T, Rossi G, Mani P, Nowotny N. Usutu Virus, Italy. 1996. Emerg Infect Dis. (2013) 19:274-7. doi: 10.3201/eid1902.121191

27. Scaramozzino N, Crance J, Jouan A, Briel DADE. Comparison of flavivirus universal primer pairs and development of a rapid, highly sensitive heminested reverse transcription-PCR assay for detection of flaviviruses targeted to a conserved region of the NS5 gene sequences. J Clin Microbiol. (2001) 39:1922-7. doi: 10.1128/JCM.39.5.1922-1927.2001

28. Sánchez-Seco MP, Rosario D, Domingo C, Hernández L, Valdés K, Guzmán MG, et al. Generic RT-nested-PCR for detection of flaviviruses using degenerated primers and internal control followed by sequencing for specific identification. J Virol Methods. (2005) 126:101-9. doi: 10.1016/j.jviromet.2005.01.025

29. Patel P, Landt O, Kaiser M, Faye O, Koppe T, Lass U, et al. Development of one-step quantitative reverse transcription PCR for the rapid detection of flaviviruses. Virol J. (2013) 10:58. doi: 10.1186/1743-422X-10-58

30. Johnson N, Wakeley PR, Mansfield KL, McCracken F, Haxton B, Phipps LP, et al. Assessment of a novel real-time pan-flavivirus RTpolymerase chain reaction. Vector-Borne Zoonot Dis. (2010) 10:66571. doi: $10.1089 / v b z .2009 .0210$

31. Moureau G, Temmam S, Gonzalez JP, Charrel RN, Grard G, De Lamballerie X. A real-time RT-PCR method for the universal detection and identification of flaviviruses. Vector-Borne Zoonot Dis. (2007) 7:46777. doi: $10.1089 / \mathrm{vbz} .2007 .0206$ 
32. Vina-Rodriguez A, Sachse K, Ziegler U, Chaintoutis SC, Keller M, Groschup $\mathrm{MH}$, et al. a novel pan- flavivirus detection and identification assay based on RT-qPCR and microarray. Biomed Res Int. (2017) 2017:4248756. doi: 10.1155/2017/4248756

33. Dyer J, Chisenhall DM, Mores CN. A multiplexed TaqMan assay for the detection of arthropod-borne flaviviruses. J Virol Methods. (2007) 145:913. doi: 10.1016/j.jviromet.2007.05.001

34. Del Amo J, Sotelo E, Fernández-Pinero J, Gallardo C, Llorente F, Agüero M, et al. A novel quantitative multiplex real-time RT-PCR for the simultaneous detection and differentiation of West Nile virus lineages 1 and 2, and of Usutu virus. J Virol Methods. (2013) 189:321-7. doi: 10.1016/j.jviromet.2013.02.019

35. Buitrago D, Rocha A, Tena-Tomás C, Vigo M, Agüero M, Jiménez-Clavero MA. Real-time fluorogenic reverse transcription polymerase chain reaction assay for the specific detection of Bagaza virus. J Vet diagn Investig. (2012) 24:959-63. doi: 10.1177/1040638712452723

36. Sotelo E, Gutierrez-Guzmán AV, Del Amo J, Llorente F, El-Harrak M, PérezRamírez E, et al. Pathogenicity of two recent Western Mediterranean West Nile virus isolates in a wild bird species indigenous to Southern Europe: the red-legged partridge. Vet Res. (2011) 42:11. doi: 10.1186/1297-9716-42-11

37. Del Amo J, Llorente F, Figuerola J, Soriguer RC, Moreno AM, Cordioli P, et al. Experimental infection of house sparrows (Passer domesticus) with West Nile virus isolates of Euro-Mediterranean and North American origins. Vet Res. (2014) 45:33. doi: 10.1186/1297-9716-45-33

38. Cano-Gómez C, Llorente F, Pérez-Ramírez E, Soriguer RC, Sarasa M, Jiménez-Clavero MÁ. Experimental infection of grey partridges with Bagaza virus: pathogenicity evaluation and potential role as a competent host. Vet Res. (2018) 49:44. doi: 10.1186/s13567-018-0536-8

39. Bournez L, Umhang G, Faure E, Boucher J-M, Boué F, Jourdain E, et al. Exposure of wild ungulates to the usutu and tick-borne encephalitis viruses in France in 2009 - 2014 : evidence of undetected flavivirus circulation a decade ago. Viruses. (2020) 12:10. doi: 10.3390/v12010010

40. Nikolay B, Diallo M, Boye CSB, Sall AA. Usutu virus in Africa. Vector Borne Zoonot Dis. (2011) 11:1417-23. doi: 10.1089/vbz.2011.0631

41. Mannasse B, Mendelson E, Orshan L, Mor O, Shalom U, Yeger T, et al. Usutu virus RNA in mosquitoes, Israel, 2014-2015. Emerg Infect Dis. (2017) 23:1699-702. doi: 10.3201/eid2310.171017
42. Steyn J, Botha EM, Lourens C, Coetzer JAW, Venter M. Bagaza virus in Himalayan monal pheasants, South Africa, 2016-2017. Emerg Infect Dis. (2019) 25:2299-302. doi: 10.3201/eid2512.1 90756

43. Johnson N, Voller K, Phipps LP, Mansfield K, Fooks AR. Rapid molecular detection methods for arboviruses of livestock of importance to northern Europe. J Biomed Biotechnol. (2012) 2012:719402. doi: 10.1155/2012/719402

44. Yan P, Zhao Y, Zhang X, Xu D, Dai X, Teng Q, et al. An infectious disease of ducks caused by a newly emerged Tembusu virus strain in mainland China. Virology. (2011) 417:1-8. doi: 10.1016/j.virol.2011. 06.003

45. Su J, Li S, Hu X, Yu X, Wang Y, Liu P, et al. Duck egg-drop syndrome caused by BYD virus, a new Tembusu-related flavivirus. PLoS ONE. (2011) 6:e18106. doi: 10.1371/journal.pone.0018106

46. Thontiravong A, Ninvilai P, Tunterak W, Nonthabenjawan N, Chaiyavong $\mathrm{S}$, Angkabkingkaew $\mathrm{K}$, et al. Tembusu-Related Flavivirus in Ducks, Thailand. Emerg Infect Dis. (2015) 21:2164-7. doi: 10.3201/eid2112.1 50600

47. Liu P, Lu H, Li S, Moureau G, Deng Y-Q, Wang Y, et al. Genomic and antigenic characterization of the newly emerging Chinese duck egg-drop syndrome flavivirus : genomic comparison with tembusu and sitiawan viruses. J Gen Virol. (2012) 93:2158-70. doi: 10.1099/vir.0.04 3554-0

Conflict of Interest: The authors declare that the research was conducted in the absence of any commercial or financial relationships that could be construed as a potential conflict of interest.

Copyright (c) 2020 Elizalde, Cano-Gómez, Llorente, Pérez-Ramírez, Casades-Martí, Aguilera-Sepúlveda, Ruiz-Fons, Jiménez-Clavero and Fernández-Pinero. This is an open-access article distributed under the terms of the Creative Commons Attribution License (CC BY). The use, distribution or reproduction in other forums is permitted, provided the original author(s) and the copyright owner(s) are credited and that the original publication in this journal is cited, in accordance with accepted academic practice. No use, distribution or reproduction is permitted which does not comply with these terms. 